\title{
Influence of long term silicone implantation on type II collagen induced arthritis in mice
}

\author{
Caralee J Schaefer, W Dwayne Lawrence, Paul H Wooley
}

\begin{abstract}
Objectives-The use of silicone implants in cosmetic and reconstructive surgery has been implicated in the development of autoimmune connective tissue diseases. Previous investigation of the influence of short-term silicone implantation using an experimental model of rheumatoid arthritis revealed no adverse influence upon disease despite the generation of autoantibodies against silicone bound proteins. This study was designed to examine the influence of long term implantation of different forms of silicone in collagen induced arthritis.

Methods-DBA/1 mice were surgically implanted with silicone elastomers, gel or oil nine months before immunisation with type II collagen emulsified in Freund's incomplete adjuvant. The incidence and severity of arthritis, antibodies to type II collagen, and serum cytokines were assessed and compared with sham implanted mice. Silicone implants were recovered, and autoantibodies to silicone bound proteins evaluated in arthritic and non-arthritic mice.
\end{abstract}

Results-Immunisation with CII/FIA resulted in a $30 \%$ arthritis incidence in sham implanted DBA/1 mice. Long term silicone implantation resulted in an increased incidence of arthritis, with a significant increase of $90 \%$ arthritis in animals implanted with silicone elastomers. Animals implanted with silicone elastomer also developed foreign body sarcomas during the study. Serum concentrations of interleukin 10 were increased in mice implanted with elastomers and immunised with CII/FIA, while interleukin 5 concentrations were significantly diminished in these mice. The production of autoantibodies to autologous silicone bound proteins, including anti-type I collagen antibody, was also attributed to the implantation of either silicone gel or silicone elastomer in type II collagen immunised animals.

Conclusions-These data suggest that long term silicone implantation results in both the production of autoantibodies to connective tissue antigens and increased susceptibility to an experimental model of autoimmune disease.

(Ann Rheum Dis 1999;58:503-509)

It is estimated that between 1 million and 2.2 million women have received silicone implants for reconstructive or cosmetic surgery in the
United States and Canada since $1962 .{ }^{1}$ Silicone was initially believed to be ideal for implantation, because of the fact that it did not seem to elicit a biological response. In recent years, however, evidence has mounted suggesting that silicone products may not be biologically inert, and that their implantation may result in a variety of tissue and immunological reactions. ${ }^{2}$ Silicone implants have been implicated in the development of autoimmune connective tissue diseases, including rheumatoid arthritis (RA). The safety of silicone implants has therefore become the focus of much controversy in both the scientific community and the lay press. It is postulated that silicone may act as an "adjuvant" in certain people with silicone implants, and may trigger the development of clinical autoimmune disease in genetically susceptible people. It is proposed that the silicone implant surface may provide an adjuvant-like activity to native macromolecules that adhere to the hydrophobic silicone surface and become immunogenic. The properties of silicone that may promote adjuvant activity are currently unclear.

Type II collagen induced arthritis (CIA) in mice is an experimental model of arthritis with a number of pathological, immunological and genetic features in common with RA. ${ }^{3}$ This experimental disease model is induced by immunisation of susceptible mice with type II collagen (CII), a major component of joint cartilage. Disease susceptibility is regulated by the class II major histocompatibility gene locus, which is analogous to the association of RA with HLA-DR4. A progressive and inflammatory arthritis develops in the majority of immunised animals, characterised by erythema and oedema that causes initial paw width increases of $100 \%$ in affected limbs. The arthritis progresses from inflammation to joint distortion and spondylitis, and histopathology of affected joints reveals synovitis, pannus formation, and cartilage and bone erosions. Laboratory findings in CIA mice include a vigorous immune response to autologous type II collagen, ${ }^{34}$ hypergammaglobulinaemia and increased acute phase proteins. ${ }^{5}$ Several cytokines involved in the inflammatory response clearly mediate the arthritogenic reaction to collagen in susceptible mice, including interleukin $1 \beta$ (IL1 $\beta$ ), ${ }^{6} 7$ gamma interferon (IFN $\gamma),{ }^{8}$ and tumour necrosis factor (TNF). ${ }^{9}{ }^{10}$

The DBA/1 mouse strain was selected for investigation, as this strain is particularly prone to the development of arthritis. In addition to the response to collagen, DBA/ 1 mice develop arthritis on injection with the mineral oil pristane, ${ }^{11}$ and also develop arthritis 
spontaneously at a low frequency, ${ }^{12}$ which suggests that this strain expresses an underlying susceptibility to joint disease. Short-term silicone implantation in DBA/1 mice did not result in an increase in the incidence or severity of arthritis. ${ }^{13}$ However, silicone implantation did change cytokine levels and resulted in the development of novel autoantibodies directed against silicone bound proteins (SBPs). Several studies of patients with silicone implants have suggested that there may be latent effects of silicone, with symptoms of connective tissue disease occurring several years after implantation. ${ }^{14-16}$ It seems unlikely that the 73 day exposure to silicone in our previous study would have revealed any latent effects of silicone implantation. Therefore, this study was conducted to evaluate the long term effects of silicone implantation in an animal model of RA.

\section{Methods}

ANIMALS

DBA/1LacJ mice 8 weeks of age were obtained from Jackson Labs (Bar Harbor, Maine) and housed in microisolator cages in the Department of Laboratory Animal Resources at Wayne State University. All mice were quarantined for two weeks before experimentation, and all procedures were approved by the Animal Investigation Committee, Wayne State University.

\section{SILICONE IMPLANTS}

Sterile silicone elastomer shells were provided by McGhan (Santa Barbara, CA), and silicone gel and oil were obtained from Dow Corning (Midland, MI). Silicone elastomer segments were cut from a silicone implant and resterilised by ethylene oxide exposure at the Central Sterilization facility at Hutzel Hospital, Detroit, MI.

IMPLANTATION OF SILICONE AND INDUCTION OF ARTHRITIS

Animals were divided into implantation and immunisation groups of 10 mice (table 1). Mice were anaesthetised with sodium pentobarbital $(60 \mathrm{mg} / \mathrm{kg})$ and implanted subcutaneously with silicone elastomer, silicone gel, silicone oil or saline (sham implantation) through a $0.5 \mathrm{~cm}$ dorsal incision. Surgical wounds were closed with wound clips. Nine months after implantation, DBA/1 mice were immunised with either $100 \mu \mathrm{g}$ bovine type II collagen (the generous gift of Dr Robert Karvonen, Wayne State University, Detroit,

Table 1 Implantation and immunisation groups of $D B A / 1$ mice

\begin{tabular}{llll}
\hline Group & Implantation & Immunisation & Number of mice \\
\hline 1 & Sham & FIA & 10 \\
2 & Sham & CII/FIA & 10 \\
3 & Silicone oil & FIA & 5 \\
4 & Silicone oil & CII/FIA & 9 \\
5 & Silicone gel & FIA & 9 \\
6 & Silicone gel & CII/FIA & 9 \\
7 & Silicone & FIA & 10 \\
8 & elastomer & CII/FIA & 10 \\
& Silicone & & \\
\hline
\end{tabular}

$\mathrm{MI}$ ), emulsified in $100 \mu \mathrm{l}$ of Freund's incomplete adjuvant (FIA) (Fisher Scientific, Pittsburgh, PA) or $100 \mu$ l of incomplete adjuvant emulsion alone.

\section{ASSESSMENT OF ARTHRITIS}

Mice were weighed weekly, and overall health status noted. Mice were monitored by daily examination for the onset of disease, which typically begins as erythema and oedema of the ankle or wrist. After the onset of CIA limbs were assigned a clinical score based on the following scale; $0=$ normal, $1=$ erythema and oedema, 2=joint distortion, $3=$ joint ankylosis. ${ }^{3}$ Mice without signs of arthritis 10 weeks after immunisation were considered disease negative. Implants were recovered at the termination of the study, 12 months after implantation and 10 weeks after collagen immunisation, for the analysis of SBPs.

HISTOPATHOLOGY OF FOREIGN BODY SARCOMAS Foreign body tumours in mice were removed by dissection, and fixed in neutral buffered formalin for 48 hours. After standard histological dehydration and paraffin wax embedding procedures, $5 \mu \mathrm{m}$ sections were mounted on $1 "$ $\times 3$ " glass slides and stained using haematoxylin and eosin ( $\mathrm{H}$ and $\mathrm{E})$. Individual tumour sections were evaluated in a blinded manner to determine the tumour morphology and classification.

SEROLOGICAL EVALUATION

The level and isotype of the antibody response to type II collagen was assessed using an ELISA assay described previously. ${ }^{11}$ Nunc 96 well Maxi-Sorb ELISA plates (Fisher Scientific, Pittsburgh, PA) were coated with $3 \mu \mathrm{g} /$ well of type II collagen overnight at $4^{\circ} \mathrm{C}$. Plates were washed three times with phosphate buffered saline (PBS) $/ 0.05 \%$ Tween, and blocked overnight at $4^{\circ} \mathrm{C}$ by the addition of $\mathrm{PBS} / 5 \%$ non-fat dry milk. Plates were again washed three times, and serum samples diluted $1 / 1000$ in $\mathrm{PBS} / 5 \%$ non-fat dry milk were dispensed in triplicate. The plates were incubated overnight at $4^{\circ} \mathrm{C}$, and washed six times. One hundred microlitres goat antimouse Ig conjugated with alkaline phosphatase (Fisher Scientific, Pittsburgh, PA), diluted $1 / 500$ in PBS $/ 5 \%$ non-fat dry milk were added, and the incubation continued for two hours at $37^{\circ} \mathrm{C}$. Alternatively, goat antibodies specific for murine $\operatorname{Ig} M, \operatorname{IgA}, \operatorname{IgG} 1, \operatorname{IgG} 2 \mathrm{a}$, $\operatorname{IgG} 2 b$ and IgG3 were used to determine isotype variation in the response. After washing, $100 \mu \mathrm{l}$ paranitrophenyl phosphate solution (PNPP tablets, Sigma, St Louis, MO) in diethylanolamine buffer were added to each well, and the reaction allowed to proceed for 20 minutes in the dark. The plates were read at $405 \mathrm{~nm}$ using a photospectrometer (Molecular Devices), and the data analysed using the SOFTmax analytical software package.

Serum concentrations of interleukin $1 \beta$ (IL1 $\beta)$, tumour necrosis factor $\alpha(\mathrm{TNF} \alpha)$, IL2, and gamma interferon (IFN $\gamma$ ) were determined using commercial ELISA assays (Genzyme, Cambridge, MA) as described previously. ${ }^{13}$ Serum concentrations of IL4, IL5, 
IL10 were determined using a similar capture ELISA technique, using specific antibody pairs (Pharmingen, San Diego, CA). Levels were determined by regression analysis from the titration curve constructed using a purified recombinant murine cytokine.

PROTEIN EXTRACTION FROM SILICONE IMPLANTS Silicone elastomer, gel, and oil implants were recovered from mice at the termination of the study for the analysis of proteins adherent to the silicone surfaces. Recovered implants were pooled into groups: (1) silicone elastomer implants from mice with arthritis, (2) silicone elastomer implants from mice without arthritis, (3) gel implants from mice with arthritis, (4) gel implants from mice without arthritis, (5) oil implants recovered from mice with arthritis and (6) oil implants recovered from mice without arthritis. Proteins were recovered from implants using techniques described previously, ${ }^{13}$ which are based upon exposure to glycine- $\mathrm{HCl}$ buffer ( $\mathrm{pH} 2.8)$ followed by immersion in $4 \mathrm{M}$ guanidine solution. Recovered protein extract solutions were concentrated, and the amount of protein extracted from the silicone implants was determined by a BCA protein assay commercial kit.

\section{IMMUNOLOGICAL ANALYSIS OF SBPS}

Immunoblot (dot blot) analysis, SDS-PAGE, and western blotting was performed on the extract solutions as described previously. ${ }^{13}$ One microlitre of each implant extract solution was pipetted onto a nitrocellulose paper strip, and probed for reactivity with goat antimouse immunoglobulin. Silicone bound proteins were electrophoresed under reducing conditions according to the method of Laemelli, ${ }^{17}$ silver stained using a commercial kit (BioRad, Hercules, CA), and image analysed to determine the number and molecular weight of the protein bands. Western blot analysis was performed to characterise the proteins extracted from the silicone implants. After electrophoretic separation, the proteins were transferred to a nitrocellulose membrane, and reacted with sera from the corresponding

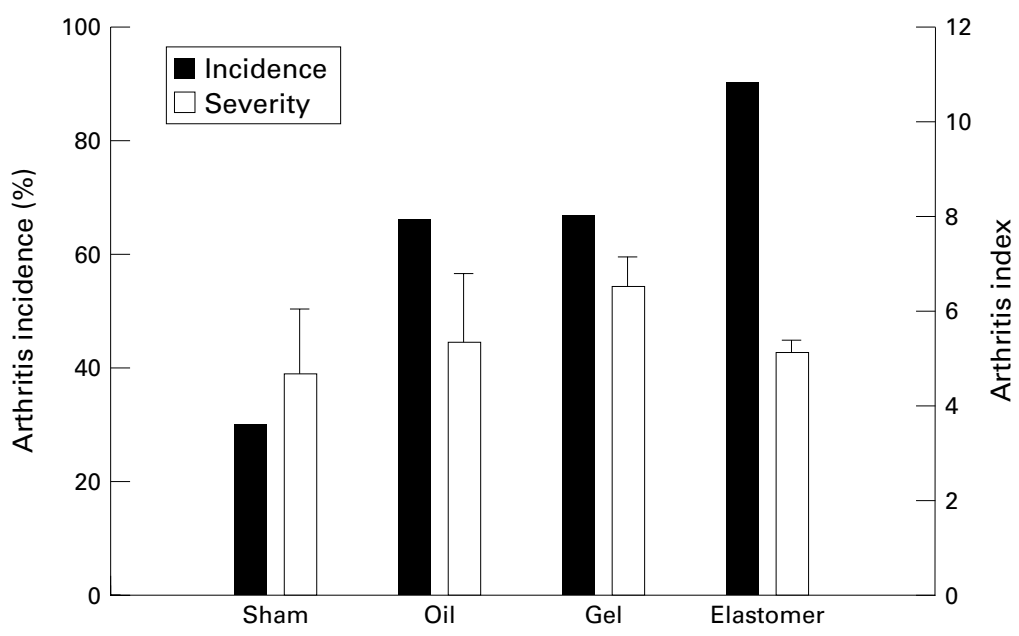

Figure 1 The per cent incidence and severity of arthritis in DBA/1 mice implanted with various forms of silicone. The severity is shown as the cumulative average per group based on the following scale: $0=$ normal, $1=$ erythema and oedema, $2=$ joint distortion, $3=$ joint ankylosis. silicone implanted mice. The membranes were then incubated with goat antimouse Ig conjugated to alkaline phosphatase (Fisher Scientific, Pittsburgh, PA), washed and placed into an aqueous substrate solution (Sigma Fast BCIP/NBT tablets; Sigma, St Louis, MO) with gentle agitation for 10 minutes. The number of autoantibody reactive proteins extracted from the silicone implant surface were then determined.

\section{DATA ANALYSIS}

Incidence of disease between experimental groups were tested using $\chi^{2}$ analysis. Comparisons of clinical (onset and severity), serological, and cellular data between groups were made using the Mann-Whitney $U$ test for nonparametric data.

\section{Results}

INCIDENCE AND SEVERITY OF CIA

Collagen arthritis incidence was evaluated in mice after nine months of implantation alone, followed by 10 weeks post collagen immunisation, giving a total exposure to silicone of approximately one year. The immunisation of sham implanted DBA/1 mice with collagen emulsified in incomplete Freund's adjuvant (CII/FIA) resulted in a $30 \%$ arthritis incidence, which represents a sub-optimal incidence of disease compared with the results obtained after immunisation with complete Freund's adjuvant, where $80 \%$ arthritis incidence occurred. ${ }^{4}{ }^{13}$ Figure 1 shows the per cent incidence of arthritis in silicone implanted and sham implanted control mice immunised with CII/FIA. Most animals survived this extended study period; however, five control mice in the silicone oil control group did succumb to the effects of anaesthesia during a routine bleed. Silicone elastomer implanted mice immunised with CII/FIA had an arthritis incidence of $90 \%$, which was significantly higher $(p<0.01)$ than the sham implanted control animals. Silicone oil and silicone gel implanted mice immunised with CII/FIA also increased incidence of arthritis $(66 \%$ incidence in both groups); however these increases did not achieve statistical significance compared with the sham implanted mice. The arthritis severity at the conclusion of the experiment in sham implanted DBA/1 mice immunised with CII/ FIA was similar to the disease observed in animals immunised with complete adjuvant. ${ }^{13}$ The mean severity scores (fig 1) in sham implanted control mice immunised with CII/FIA was 4.67 (SD 2.5), and although silicone implanted arthritic mice had modestly increased mean disease scores compared with the sham implanted controls (irrespective of the silicone form), none of these increases achieved statistical significance. Silicone implantation was without effect upon disease onset, with arthritis occurring with a mean onset day of $47-48$ for all groups. Silicone implantation in DBA/1 animals immunised with incomplete adjuvant alone did not result in disease after 12 months of silicone exposure. 


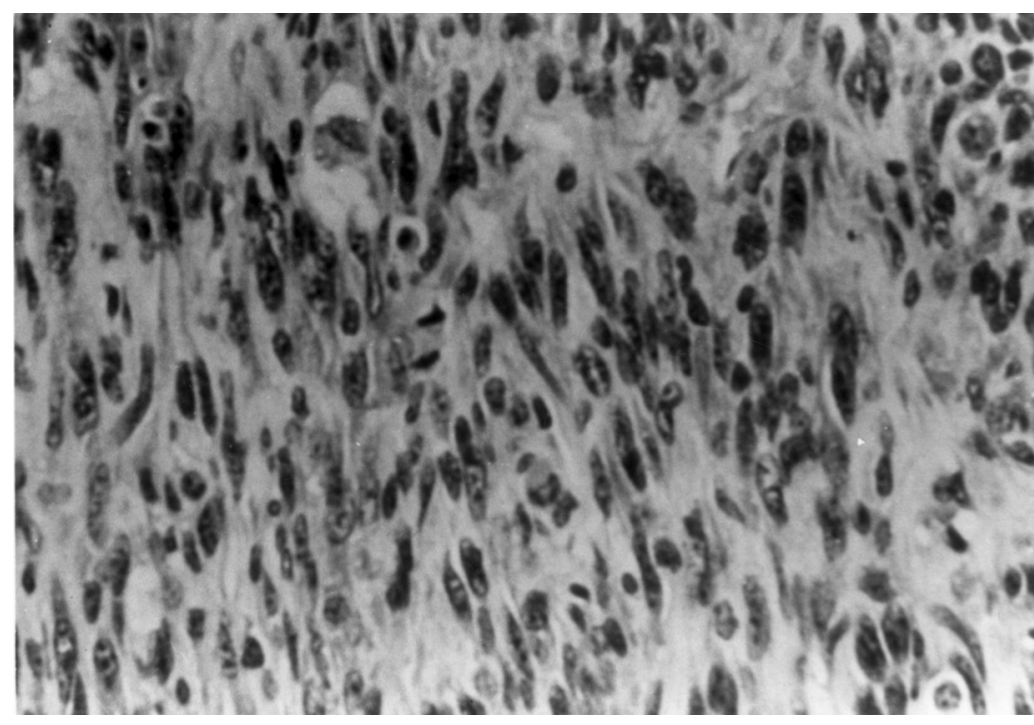

Figure 2 A photograph of a haematoxylin and eosin section of a foreign body sarcoma dissected from a mouse implanted with silicone elastomer.

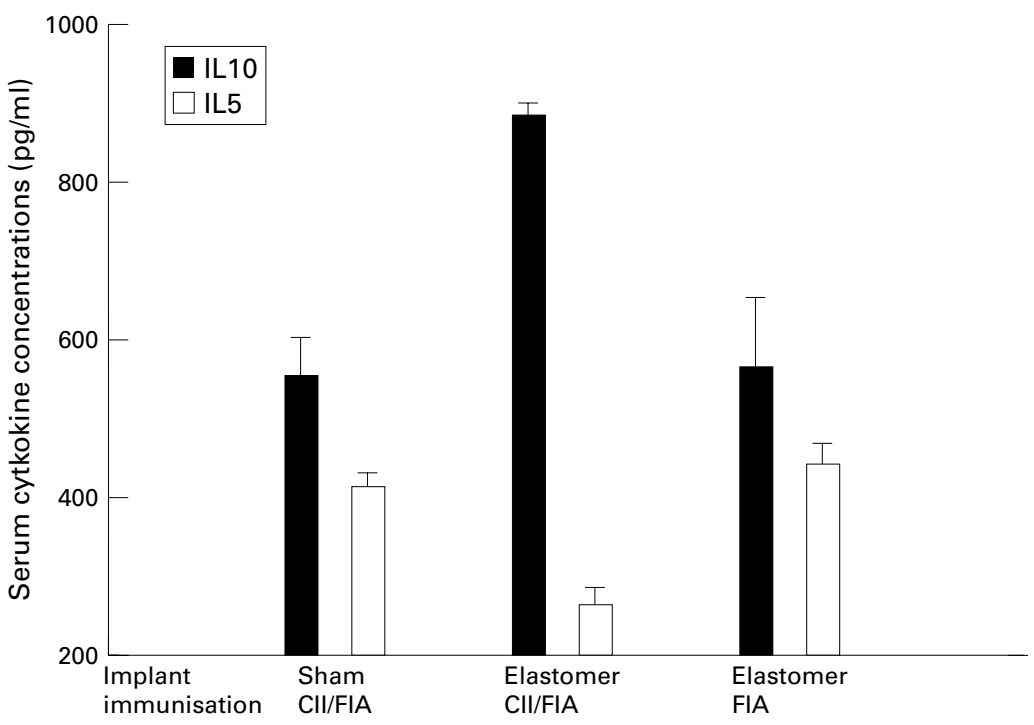

Figure 3 Serum cytokine concentrations (IL10 and IL5) in DBA/1 mice implanted with silicone elastomers and control mice.

Table 2 Proteins extracted from silicone implants in latency study

\begin{tabular}{llcc}
\hline Implant & Arthritis & $\begin{array}{c}\text { Protein recovered } \mu \mathrm{g} / \\
\text { implant (glycine) }\end{array}$ & $\begin{array}{l}\text { Protein recovered } \mu \mathrm{g} / \\
\text { implant (guanidine) }\end{array}$ \\
\hline Silicone gel & Yes & 66.0 & 126.1 \\
Silicone gel & No & 28.2 & 63.7 \\
Silicone oil & Yes & 128.5 & 138.8 \\
Silicone oil & No & 125.3 & 173.8 \\
Silicone elastomer & Yes & 38.2 & 27.2 \\
Silicone elastomer & No & 28.1 & 21.3 \\
\hline
\end{tabular}

FOREIGN BODY SARCOMAS

Three mice implanted with silicone elastomers in this experiment developed foreign body sarcomas before the conclusion of the study. The presence of arthritis did not have an effect on the incidence of sarcomas in these mice, as one animal not immunised with collagen developed a sarcoma in this study. Mice implanted with silicone oil or gel, or sham implanted mice, did not develop foreign body sarcomas, resulting in a significant increase in foreign body sarcoma incidence $(p<0.01)$ in the elastomer group compared with any of the other groups. Figure 2 shows a photomicrograph of one of the foreign body sarcomas removed from a silicone elastomer implanted mouse. Histopathological examination of all the foreign body sarcomas invariably revealed a high grade and markedly cellular malignant neoplasm with a nonspecific spindle cell pattern (fig 2). Sarcomatous nuclei were enlarged, hyperchromatic, and focally pleomorphic, with coarsely clumped chromatin. Mitotic activity was brisk, with a index between 5 and 10 mitotic figures per 10 high power field examined. Abnormal mitotic figures were evidence throughout the tumour. The sarcomas invaded the surrounding fibroconnective soft tissues and fat as irregular, infiltrative tongues and islands.

COLLAGEN ARTHRITIS SEROLOGY

The levels of anti-CII antibodies assayed four weeks after immunisation, at the time of disease onset (were applicable), and at the termination of the study, were equivalent in all CII/FIA immunised mice irrespective of their implantation status. High antibody titres (OD $>1.500$ ), similar to those recorded in mice immunised using complete Freund's adjuvant, ${ }^{13}$ were observed in all animals. No significant variations in the distribution of the isotypes of the anti-collagen antibodies were attributable to silicone implantation, with IgG1 appearing as the predominant isotype in all CII/FIA immunised mice. Silicone implantation in DBA/1 animals immunised with incomplete adjuvant alone did not result in the elicitation of antibodies reactive to type II collagen at any point in the study.

Serum cytokine concentrations were assayed at the time of disease onset (where applicable), and at the termination of the study. Silicone implantation did not induce marked variations in the serum concentrations of IL $1 \beta, \mathrm{TNF} \alpha$, IL2, IL4, or $\gamma$ IFN in mice immunised with CII/FIA. However, the concentrations of IL10 in mice implanted with silicone elastomer and immunised with CII/FIA were significantly increased over the IL10 levels observed in sham implanted CII/FIA immunised mice (fig 3). This increase was not observed in mice implanted with silicone elastomer and immunised with FIA alone, or in mice implanted with silicone oil or gel. In contrast, terminal serum values of IL5 concentration were significantly diminished in mice implanted with silicone elastomer and immunised with $\mathrm{CII} /$ FIA compared with controls.

ANALYSIS OF SBPS

At the termination of the experiment silicone implants were recovered from the mice for analysis of the proteins adherent to the silicone surfaces. The majority of the gel and elastomer implants were surrounded by a fibrous capsule, which was removed by dissection. Table 2 shows the levels of proteins from the explants. The highest level of protein recovery was achieved from silicone oil explants, compared with either silicone gel or elastomers. In general, the guanidine $\mathrm{HCl}$ extraction recovered higher protein levels than the glycine extraction, with the exception of protein recovery from the elastomer explants. The presence of arthritis in mice appeared to increase protein 


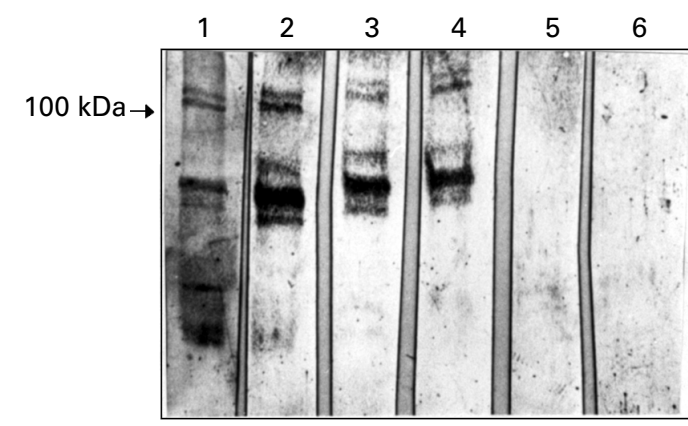

Figure 4 Western blot detecting autoantibodies to a high molecular weight silicone bound protein in silicone implanted mice. Arrow indicates reactive band (approximately $100 \mathrm{kDa}$ ). Lane 1: proteins extracted from arthritic mice with gel implants; lane 2: non-arthritic mice/gel implants; lane 3: arthritic micelelastomer implants; lane 4: non-arthritic micelelastomer implants; lane 5: arthritic mice/oil implants; lane 6: non-arthritic mice/oil implants.

adherence to silicone implants, particularly for silicone gel implants where protein recovery from arthritic explants was approximately twice the protein recovery from non-arthritic explants.

IMMUNOLOGICAL ANALYSIS OF SBPS

Western blot analysis was carried out to assay for the development of autoantibodies to SBPs in arthritic and non-arthritic mice. Guanidine protein extracts immobilised on nitrocellulose were probed using sera pools from the corresponding (autologous) groups of mice. Bands coincident with immunoglobulins were detected in the proteins extracts from silicone gel implants from both arthritic and disease free mice, and in proteins extracted from elastomer implants from arthritic mice. This result was expected as the protein extracts were positive for immunoglobulin by immunoblotting; therefore these bands were disregarded in the evaluation of autoantibodies.

Serum autoantibodies reactive with a high molecular weight (approximately $100 \mathrm{kDa}$ ) doublet band in the corresponding extract were detected in several groups of implanted mice (fig 4). This combination of serum autoantibody and silicone bound autoantigen was detected in collagen immunised mice implanted with either silicone gel or silicone elastomer (irrespective of their arthritis status), but was absent in mice implanted with silicone oil, or in mice implanted with silicone (any form) and immunised with adjuvant alone. Furthermore, sera from non-implanted mice failed to react with any SBPs. As the antigen reactive pattern was highly suggestive of type I collagen, western blots were used to further characterise

Table 3 Western blot analysis of autoantibodies to silicone bound proteins (SBPS)

\begin{tabular}{lllll}
\hline Implant & Immunisation & Arthritis & $\begin{array}{l}\text { Number of } \\
\text { reactive bands }\end{array}$ & MW of bands $(k D a)$ \\
\hline Silicone gel & CII/FIA & Yes & 2 & $100,61.6$ \\
Silicone gel & CII/FIA & No & 5 & $100,61.6,51.9,36.1,25.2$ \\
Silicone gel & FIA & No & 0 & - \\
Silicone oil & CII/FIA & Yes & 0 & - \\
Silicone oil & CII/FIA & No & 0 & - \\
Silicone oil & FIA & No & 0 & - \\
Silicone elastomer & CII/FIA & Yes & 3 & $100,61.6,51.9$ \\
Silicone elastomer & CII/FIA & No & 0 & - \\
Silicone elastomer & FIA & No & 0 & - \\
& & & & \\
\hline
\end{tabular}

the autoantibodies. Bovine type I collagen was electrophoresed and transferred to nitrocellulose, and the antibody binding observed to the approximately $100 \mathrm{kDa}$ doublet bands was essentially identical to the reaction pattern seen against the approximately $100 \mathrm{kDa}$ bands in the SBP extract, confirming reactivity with type I collagen. No reaction was seen using sera from silicone oil implanted animals, sham implanted animals, or any pre-bleed sera drawn before silicone implantation. Four other autoantigen/autoantibody reactions were seen in silicone implanted mice using the western blot technique, predominantly in non-arthritic animals implanted with silicone gel. The specificity of these autoantibodies remains to be characterised. Table 3 summarises the total number of immunoreactive bands and the molecular weights of the target proteins detected by western blot using sera from the different implanted DBA/1 mice.

\section{Discussion}

Silicone implants have been implicated in the development of autoimmunity, and these implications have resulted in a ban on these devices. ${ }^{18}$ Concerns remain to date that a putative link exists between silicone implants and connective tissue disease, although an association between silicone and immune disorders is not strikingly obvious. ${ }^{19}$ To date, epidemiological studies have failed to strongly link silicone implants and autoimmune disorders, although one study did suggest a small increase in relative risk. ${ }^{20}$ There are many variables that complicate epidemiological investigations of silicone implants and disease, including the rare prevalence of both implants and autoimmunity, as well as physical and chemical variations among the implant materials. Our investigation controlled for several of these variables, in an established animal model of autoimmunity where the genetic and clinical aspects of disease are well known.

The findings in this study seem to be the most direct indication of an effect of silicone implantation on autoimmunity. We previously investigated the influence of silicone implantation in this experimental model of arthritis, ${ }^{13}$ and concluded that despite the provocation of autoantibodies attributable to silicone implantation there was little evidence of an exacerbation of autoimmune disease. This study has several relevant differences that may contribute to the new findings. Our initial investigation examined silicone implantation during a relatively short-term implantation of 73 days. Several studies of patients with silicone implants have suggested that there may be latent effects of silicone, with symptoms of connective tissue disease occurring several years after implantation. ${ }^{14-16}$ This current long term investigation, with a total silicone exposure time of 12 months, represents a major portion of the life span of the DBA/1 mouse. The original study examined intraperitoneal silicone implantation, which was intended to maximise silicone exposure to macrophages, and thus facilitate potential inflammatory cytokine production. However, intraperitoneal implantation does not 
accurately resemble typical sites of silicone implantation in patients, and this concern was met by using subcutaneous implantation in this study. Previous experiments examined the influence of silicone on DBA/ 1 mice immunised with type II collagen in Freund's complete adjuvant. The control disease incidence $(80 \%)$ limited the capacity to detect an increase in experimental arthritis; therefore mice were immunised with CII emulsified with incomplete adjuvant (CII/FIA) to generate a suboptimal incidence of arthritis ${ }^{21}$ and provide an increased sensitivity to examine the effects of silicone implantation. These variations in experimental design have generated marked changes in the study outcome. Mice implanted with silicone elastomers nine months before immunisation with CII/FIA developed a significantly increased incidence of arthritis. The long term implantation of silicone gel and oil also increased the incidence of disease, although these increases did not reach statistical significance. This variation may reflect the physical differences between the different forms of silicone, and would suggest that silicone elastomer is capable of functioning as an adjuvant for bound proteins. It was predicted that silicone oil or gel might serve as the strongest adjuvant, as the oil implants that were recovered did yield a high level of proteins extracted from the oil surface. However, much of the silicone oil had dissipated from the injection site at the time of recovery, making a complete estimate of protein binding difficult. However, it is possible that bound protein also turns over at a high rate when bound to silicone oil, which could detract from an adjuvant effect.

Overall, these results also suggest that long term silicone implantation augments the incidence of arthritis in mice sub-optimally immunised with collagen. The mechanism by which silicone exerts this influence is not clear, as no obvious changes in the level or isotype of the antibody response to collagen were observed in silicone implanted mice. The increase in serum IL10 in elastomer implanted mice immunised with collagen might be predicted to exert an ameliorating effect upon this disease, ${ }^{22}{ }^{23}$ however, increased IL10 levels have been associated with increased antibodies to collagen ${ }^{24}$ and the production of autoantibodies in patients. ${ }^{25-27}$

In addition to influencing the arthritis incidence, the long term implantation of silicone in this study also provoked the production of antibodies to autologous SBPs, consistent with our previous work. ${ }^{13}$ One autoantibody was determined to react against type I collagen. This result is consistent with two studies that report autoantibodies to type I collagen in women with silicone implants. Tenenbaum et $a^{28}$ reported autoantibodies directed against a high molecular weight collagen-like molecule in $50 \%$ of a small group of women with silicone implants, and Rowley et $a t^{29} 30$ reported that women with silicone implants have an increased frequency of autoantibodies directed against an unusual epitope of type I collagen. Immunoglobulin bound to silicone implants was also a frequent finding in this study, consistent with both short-term silicone implantation ${ }^{13}$ and the findings of Kossovsky et $a l,{ }^{31}$ who reported immunoglobulin present in the proteins adherent to silicone breast implants in patients.

The subcutaneous implantation of plastics or glass into rats and mice has previously been used as a model of chronic inflammation, and such reactions may eventually give rise to sarcomas. ${ }^{32}$ A number of mice implanted with silicone elastomers developed foreign body sarcomas in this study. The tumours developed more than nine months after implantation, and were independent of the presence of arthritis. This result was surprising, as the $\mathrm{DBA} / 1$ mouse strain is not particularly prone to the development of foreign body sarcomas. ${ }^{33}$ Mice that were implanted with silicone gel, silicone oil, or were sham implanted did not develop foreign body sarcomas. The finding that the long term implantation of silicone elastomers may provoke foreign body sarcomas may not be applicable to the human situation, as foreign body sarcomas seem to be a rodent specific reaction not confined to silicones. ${ }^{34}$ Dow Corning silicone implant manufacturers' reported in 1987 an increased rate of fibrosarcomas in rats that had been subcutaneously implanted with silicone gel. ${ }^{36}$ Silicone associated fibrosarcomas have not been reported in any species higher than the rat, and there has been no increase overall in the incidence of breast sarcomas or other tumours in women with breast implants in the time period since silicone implants have been in use. ${ }^{37} \mathrm{Al}$ though foreign body sarcoma may be a rodent specific phenomenon, it does indicate the potential for silicone implantation to result in adverse biological effects.

The results in these studies support the hypothesis that the long term exposure to silicone may increase susceptibility to an autoimmune experimental disease, although the precise mechanism remains to be determined. The conclusions of this animal study must be related to findings with patients with silicone implants with great caution. Although several human studies suggest that autoantibodies may be influenced by silicone implantation, there is little evidence to date that silicone implantation impacts upon autoimmune disease. This experimental model of connective tissue disease suggests that although shortterm exposure to silicone was essentially benign, long term implantation of silicone may trigger the development of autoimmune disease.

1 Sanchez-Guerrero J, Colditz GA, Karlson EW, Hunter DJ, Speizer FE, Liang MH. Silicone breast implants and the risk of connective-tissue diseases and symptoms. N Engl J Med 1995;332:1666-70.

2 Cuellar ML, Scopelitis E, Tenenbaum SA, Garry RF, Silveira LH, Cabrera G, et al. Serum antinuclear antibodies in women with silicone breast implants. J Rheumatol 1995; 22:236-40.

3 Wooley PH, Luthra HS, Stuart JM, David CS. Type II collagen-induced arthritis in mice. I. Major histocompatibility complex (I region) linkage and antibody correlates. J ibility complex (I region) link

4 Wooley PH. Collagen-induced arthritis in the mouse. Methods Enzymol 1988;162:361-73. 
5 Bliven ML, Wooley PH, Pepys MB, Otterness IG. Murine type II collagen arthritis. Association of an acute-phase response with clinical course. Arthritis Rheum 1986;29: 1131-8.

6 Hom JT, Bendele AM, Carlson DG. In vivo administration with IL-1 accelerates the development of collagen-induced arthritis in mice. J Immunol 1988;141:834-41.

7 Killar LM, Dunn CJ. Interleukin-1 potentiates the development of collagen-induced arthritis in mice. Clin Sci 1989 76:535-8.

8 Cooper SM, Sriram S, Ranges GE. Suppression of murine collagen-induced arthritis with monoclonal anti-Ia antibodies and augmentation with IFN-gamma. J Immunol bodies and augment

9 Cooper WO, Fava RA, Gates CA, Cremer MA, Townes AS. Acceleration of onset of collagen-induced arthritis by intraarticular injection of tumour necrosis factor or transforming growth factor-beta. Clin Exp Immunol 1992;89:24450 .

10 Brahn E, Peacock DJ, Banquerigo ML, Liu DY. Effects of tumor necrosis factor alpha (TNF-alpha) on collagen arthritis. Lymphokine and Cytokine Research 1992;11: 253-6.

11 Wooley PH, Seibold JR, Whalen JD, Chapdelaine JM. Pristane-induced arthritis. The immunologic and genetic features of an experimental murine model of autoimmune disease. Arthritis Rheum 1989;32:1022-30

12 Holmdahl R, Jansson L, Andersson M, Jonsson R. Genetic, hormonal and behavioural influence on spontaneously developing arthritis in normal mice. Clin Exp Immunol 1992;88:467-72.

13 Schaefer CJ, Whalen JD, Knapp T, Wooley PH. The influence of silicone implantation on type II collageninduced arthritis in mice. Arthritis Rheum 1997;40:1064 72.

14 Sanchez-Guerrero J, Schur PH, Sergent JS, Liang MH. Silicone breast implants and rheumatic disease. Clinical, immunologic, and epidemiologic studies. Arthritis Rheum 1994;37:158-68.

15 Finegold I. Allergy to silicone: is it real? Compr Ther 1996; 22:393-8.

16 Solomon G. A clinical and laboratory profile of symptomatic women with silicone breast implants. Semin Arthritis Rheum 1994;24:29-37.

17 Laemmli UK. Cleavage of structural proteins during the assembly of the head of bacteriophage T4. Nature 1970;227:680-5.

18 Kessler DA. The basis of the FDA's decision on breast implants. N Engl J Med 1992;326:1713-15.

19 Duffy DM. Silicone: a critical review. Adv Dermatol 1990;5:93-107.

20 Hennekens CH, Lee I, Cook NR, Herbert NR, Karlson EW, LaMotte F, et al. Self-reported breast implants and connective tissue diseases in female health professionals. A retrospective cohort study. JAMA 1996;275:616-21.

21 Ellis JS, Chain BM, Cooke A, Ibrahim MA, Katz DR. Adjuvant composition determines the induction of type II collagen-induced arthritis. Scand J Immunol 1992;36:4956.

22 Kasama T, Strieter RM, Lukacs NW, Lincoln PM, Burdick MD, Kunkel SL. Interleukin-10 expression and chemokine regulation during the evolution of murine type II collageninduced arthritis. J Clin Invest 1995;95:2868-76.
23 Walmsley M, Katsikis PD, Abney E, Parry S, Williams RO, Maini RN, et al. Interleukin-10 inhibition of the progression of established collagen-induced arthritis. Arthritis Rheum 1996;39:495-503.

24 Stein SH, Hart TE, Hoffman WH, Hendrix CL, Gustke CJ, Watson SC. Interleukin-10 promotes anti-collagen antibody production in type I diabetic peripheral B lymbody production in type I diabetic periph

25 Llorente L, Zou W, Levy Y, Richaud-Patin Y, Wijdenes J, Alcocer-Varela J, et al. Role of interleukin 10 in the B lymphocyte hyperactivity and autoantibody production of human systemic lupus erythematosus. J Exp Med 1995; 181:839-44.

26 Krams SM, Cao S, Hayashi M, Villanueva JC, Martinez OM. Elevations in IFN-gamma, IL-5, and IL-10 in patients with the autoimmune disease primary biliary patients with the autoimmune disease primary biliary CD30. Clin Immunol Immunopathol 1996;80:311-20.

27 Fuss IJ, Strober W, Dale JK, Fritz S, Pearlstein GR, Puck $\mathrm{JM}$, et al. Characteristic T helper $2 \mathrm{~T}$ cell cytokine abnormalities in autoimmune lymphoproliferative syndrome, a syndrome marked by defective apoptosis and humoral autoimmunity. J Immunol 1997;158:1912-18.

28 Tenenbaum SA, Rice JC, Espinoza LR, Cuellar ML Plymale DR, Sander DM, et al. Use of antipolymer Plymale DR, Sander DM, et al. Use of antipolymer antibody assay in recipients

29 Teuber SS, Rowley MJ, Yoshida SH, Ansari AA, Gershwin ME. Anti-collagen autoantibodies are found in women with silicone breast implants. J Autoimmun 1993;6:36777.

30 Rowley MJ, Cook AD, Teuber SS, Gershwin ME. Antibodies to collagen: comparative epitope mapping in women with silicone breast implants, systemic lupus erythematosus with silicone breast implants, systemic lupus erythematos

31 Kossovsky N, Stassi J. A pathophysiological examination of the biophysics and bioreactivity of silicone breast implants. Semin Arthritis Rheum 1994;24:18-21.

32 Thomassen MJ, Buoen LC, Brand I, Brand KG. Foreignbody tumorigenesis in mice: DNA synthesis in surfaceattached cells during preneoplasia. J Natl Cancer Inst 1978;61:359-63.

33 Brand I, Buoen LC, Brand KG. Foreign-body tumors of mice: strain and sex differences in latency and incidence. J Natl Cancer Inst 1977;58:1443-7.

34 Brand KG, Brand I. Risk assessment of carcinogenesis at implantation sites. Plast Reconstr Surg 1980;66:591-5.

35 James SJ, Pogribna M, Miller BJ, Bolon B, Muskhelishvili L Characterization of cellular response to silicone implants in rats: implications for foreign-body carcinogenesis. Biomaterials 1997;18:667-75.

36 Anonymous. Concerning experimental animal tumors associated with silicone gel. Dow Corning Corporation. Colorado Medicine 1988;85:486-6.

37 Noone RB. A review of the possible health implications of silicone breast implants. Cancer 1997;79:1747-56.

38 Engel A, Lamm SH, Lai SH. Human breast sarcoma and human breast implantation: a time trend analysis based on SEER data (1973-1990). J Clin Epidemiol 1995;48:53944. 